\title{
DEVELOPING A WEB-BASED ONTOLOGY FOR E-BUSINESS
}

\author{
Abdel-Badeeh M. Salem \\ Research Institute of the University of Economics - Varna \\ University of Economics - Varna \\ 77, Knyaz Boris I Blvd., 9002 Varna, Bulgaria \\ abmsalem@yahoo.com \\ Silvia Parusheva \\ University of Economics - Varna \\ 77, Knyaz Boris I Blvd., 9002 Varna, Bulgaria \\ parusheva@ue-varna.bg
}

\begin{abstract}
Ontological engineering (OE) is a subset of knowledge science. Ontology is a powerful technique for knowledge management and reasoning tasks. Recently, most research of OE is related to developing robust, smart, knowledge-based systems in different domains. Nowadays, e-business, or electronic business, is the integrated execution of all business analytics processes of an enterprise by means of smart computing and informatics. The objective of this study is to develop a web-based ontology for ebusiness paradigms. In this work, five web-based ontologies were designed for the following: (a) e-business applications; (b) e-business participants; (c) e-business infrastructure; (d) e-business support areas, and (e) fields in ebusiness. The developed ontologies were implemented in ontology webbased language OWL2 using the Protégé smart tool version 5.0.0 editing environment.
\end{abstract}

Keywords: Knowledge Engineering, E-Business, E-Commerce, Web Technology, Ontology, Computer Science, Artificial Intelligence, Smart Computing.

\section{INTRODUCTION}

During the past decade, many published studies have reported that, ontological engineering is a smart tool for knowledge management ${ }^{1,2}$. Overall, the main benefits of using the OE paradigm are: (a) to share 
insights and create a mutual understanding of the structure of information among users or intelligent software agents, (b) to enable the reusability of domain knowledge, (c) to represent a domain of interest in an explicit way, (d) to differentiate domain knowledge from operational knowledge, and (e) to determine and identify domains of interest. Currently, there are applications of $\mathrm{OE}$ with industrial, biological, medical, educational, commercial, and research focuses ${ }^{3,4,5}$.

E-business is a complex term encompassing the deployment of recent Information and Communication Technologies across organizational departments considering the links to partners, suppliers, intermediaries, and customers, and including many processes - not only buying and selling goods and services, but also processing payments, servicing customers, interacting with business partners, etc. ${ }^{6}$. Authors like Wallace ${ }^{7}$ add insight on the participants in e-business, including governments and nonprofits. In sum, e-business is buying, selling, delivering, marketing, paying, and servicing for products and services as well as sharing information through networks that link business organizations and their customers, partners, allies, suppliers, agents, prospects, and competitors.

Overall, we observed that limited applications of knowledge engineering paradigms in the field of e-business are related to modeling ebusiness $^{8,9}$. Osterwalder and Pigneur use, for example, as a base for representing the e-business domain several main aspects: customer relationship, product innovation, infrastructure management, and finances, with the main goal of describing technology for creating value in online business ${ }^{9}$. The benefits of using formalized e-business models can be seen in the possibility for managers to easily communicate with each other, share views with other stakeholders ${ }^{10}$, simulate e-businesses, learn about them without the risk of the experiment threatening the organization ${ }^{11}$, favor changes if needed ${ }^{12}$, etc. Section 2 presents a brief overview of e-business. Section 3 discusses OE aspects from an AI perspective. Section 4 presents the proposed methodology for designing web-based ontologies. Section 5 discusses the results and section 6 reveals the conclusion.

\section{E-BUSINESS}

E-business involves all aspects of business, which are based on the use of informatics approaches and computer networks. Overall, comparing ebusiness and e-commerce, most researchers emphasize that e-business is a somewhat broader concept ${ }^{6,13}$. E-business refers to servicing customers, discovering knowledge, collaborating with business partners, e-government, performing e-transactions within an organization, social networks, and far 
more ${ }^{13,14}$. Moreover, some researchers are ready "to use the broadest meaning of digital commerce, which is basically equivalent to the broadest definition of e-business, and these terms can be used interchangeably"14. Ebusiness links value chains across businesses, involves efficient paradigms in the value chain, reduces costs, and improves business efficiency.

E-business has a very varied and complex framework involving many tasks, organizational units, and technological issues ${ }^{14}$. Many authors focus on different important aspects and approaches related to e-commerce and ebusiness. Some authors (Turban et al. ${ }^{14}$ ) view a wide range of applications in the area of e-business including e-purchasing, e-learning, e-government, e-marketing, online advertising, m-commerce, social commerce, collaborative commerce, online publishing, e-health, etc. Other authors (Parusheva et al. ${ }^{15}$, Joshi ${ }^{16}$ ) distinguish a special group of applications in the area of e-finance. Central e-finance applications include electronic banking, e-payments, electronic trading, and e-insurance. In turn, electronic banking has a range of applications: PC banking, internet banking, mobile banking, phone banking, TV banking, as well as, most recently, wearable banking and social media banking.

To perform these applications, organizations and companies need appropriate infrastructure and support areas. Turban et al. ${ }^{14}$ offers five support areas, which include people, public policy, marketing and advertising, support services, and business partnerships.

All authors publishing in the field of e-business pay attention to ebusiness participants. Authors like Laudon and Traver ${ }^{17}$ emphasize only the major participants (Business-to-Business and Business-to-Consumer) and examine them in detail. The first type includes participants like edistributors, e-procurement, exchanges, and industry consortia. The second type has many representatives - e-tailors, portals, community providers, content providers, etc. Other authors (Rainer et al. ${ }^{13}$ ) consider many more types of participants: Business-to-Business, Business-to-Consumer, Consumer-to-Consumer, Business-to-Employee, and e-government, which in turn includes Government-to-Customer, Government-to-Business, Government-to-Government, etc.

The new developments, maturation, and growth of e-business continue to expand. Overall, the prerequisites for this growth are the relentless evolution in ICT and the commercial approaches, which exploit this evolution ${ }^{6}$. The latest trends in e-business are related to the phenomenal growth of social media, especially of social networks such as Facebook, Twitter, and Google+, and conducting e-business via mobile devices ${ }^{14,18}$. 


\section{ONTOLOGICAL ENGINEERING ASPECTS FROM AN AI PERSPECTIVE}

From an AI perspective, OE includes a group of smart activities that focuses on development process, life cycles, building methodologies programming languages, and smart software tools. Figure 1 shows the main aspects, activities, and components of OE (for more details, see Sowa ${ }^{19}$ ). Ontologies are efficient smart tools for semantic understanding between computers (running non-homogeneous software programs) and cooperation between humans and computers. Trausan ${ }^{20}$ explained the idea that ontologies act as binders, which combine database systems and knowledgebased systems in collaboration-based models and forms.

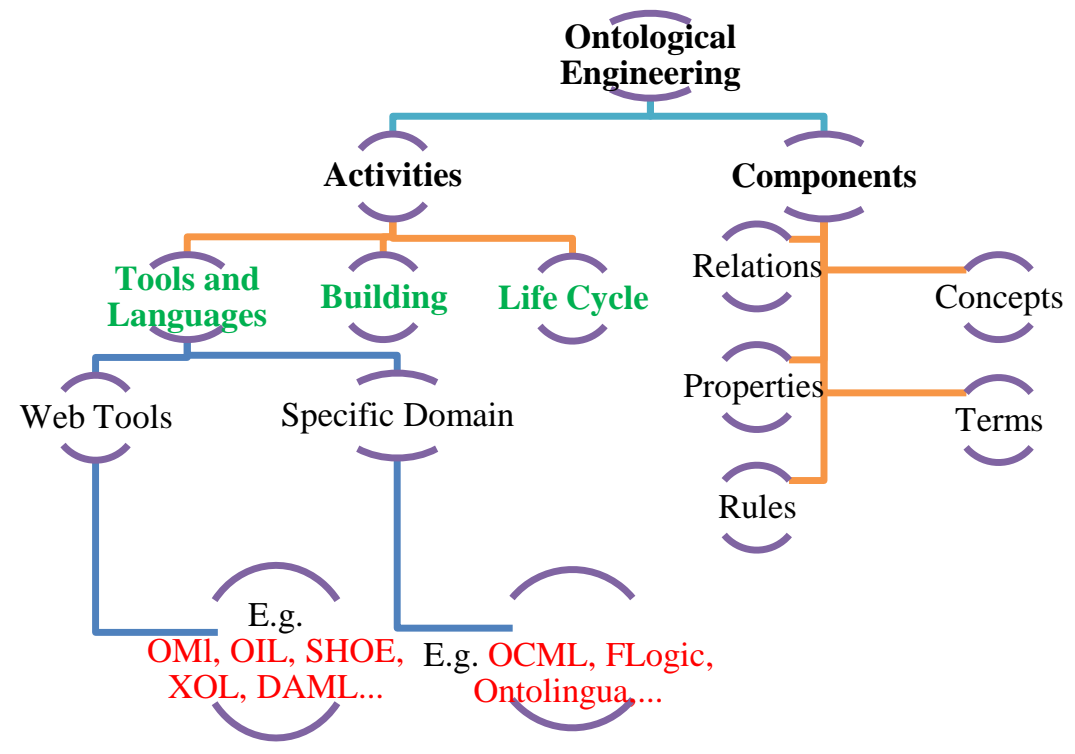

Figure 1. Activities and Components of Ontological Engineering

$\mathrm{OE}$ is still a fuzzy field of research where individual knowledge engineers employ their own developing methodologies. Ontology building requirements differ based on the method of identifying concepts. There are three common approaches:

a. "bottom-up" starts with the identification of the most harmonized and suitable concepts to the most abstract concepts.

b. "top-down" starts with the identification of the most abstract concepts to the most harmonized and suitable concepts. 
C. "middle-out" goes from the most closely related concepts to the most abstract concepts followed by the most harmonized and suitable concepts.

\section{PROPOSED KNOWLEDGE ENGINEERING METHODOLOGY FOR DEVELOPING A WEB-BASED "E-BUSINESS" ONTOLOGY}

The proposed knowledge engineering methodology for developing the web-based ontology contains several processes to be applied. The following procedure is adopted for e-business ontology:

Step 1: Organizing and scoping, in which we specify the ontology boundaries.

Step 2: Data acquisition, in which we collect data required for our task. In this respect, data was collected from publications and books in the field of e-business, e-economy, and e-commerce. Authors like Chaffey ${ }^{6}$, Wallace $^{7}$, Oswalder and Pigneur ${ }^{9}$, Rainer et al. ${ }^{13}$, Turban et al. ${ }^{14}$, Parusheva et al. ${ }^{15}$, Joshi ${ }^{16}$, Laudon and Traver ${ }^{17}$ and their scientific works in the scope of e-business are an important basis for data collection.

Step 3: Data analysis, in which we:

a. identify the main classes and class hierarchy;

b. identify the main features of classes (slots);

c. identify the facets of the slots (e.g. domain and range of a slot, cardinality, slot-value type);

d. create individuals (instances of classes).

Step 4: Development of initial ontology, in which we define classes, properties, and relations. In our developed ontology, we used ontology webbased language version 2 (OWL-2) with the smart Protégé version 5 editing environment.

Step 5: Ontology refinement, in which the initial ontology is iteratively adjusted.

\section{RESULTS AND DISCUSSION}

Building ontology in a specific domain is still a matter of skill rather than an understood engineering process. Some programming languages and smart tools have been created to support ontology development. A semantic network ( $\mathrm{SN}$ ) refers to a smart graphical group of symbols that enables the representation of knowledge in terms of interlinked nodes and arcs. It 
identifies the main objects and the relationships between objects. The implementations of SNs were first created to be applied in the AI and machine translation fields, but earlier versions have long been used in psychology, philosophy, and linguistics. What distinguishes SNs is that they present a declarative graphic representation technique that can be used to manage knowledge as well as to support automated systems for reasoning capabilities about knowledge.

Figure 2 shows the proposed architectural diagram of the semantic net of e-business based on a comprehensive analysis of the literature published during the past 10 years. This network refers to a graphic notation that enables the representation of knowledge in terms of interlinked nodes and arcs. It identifies the main objects and relationships between objects. In this net, it can be seen that there are five main super-classes namely: e-business applications, e-business participants, e-business infrastructure, e-business support areas, and fields in e-business.

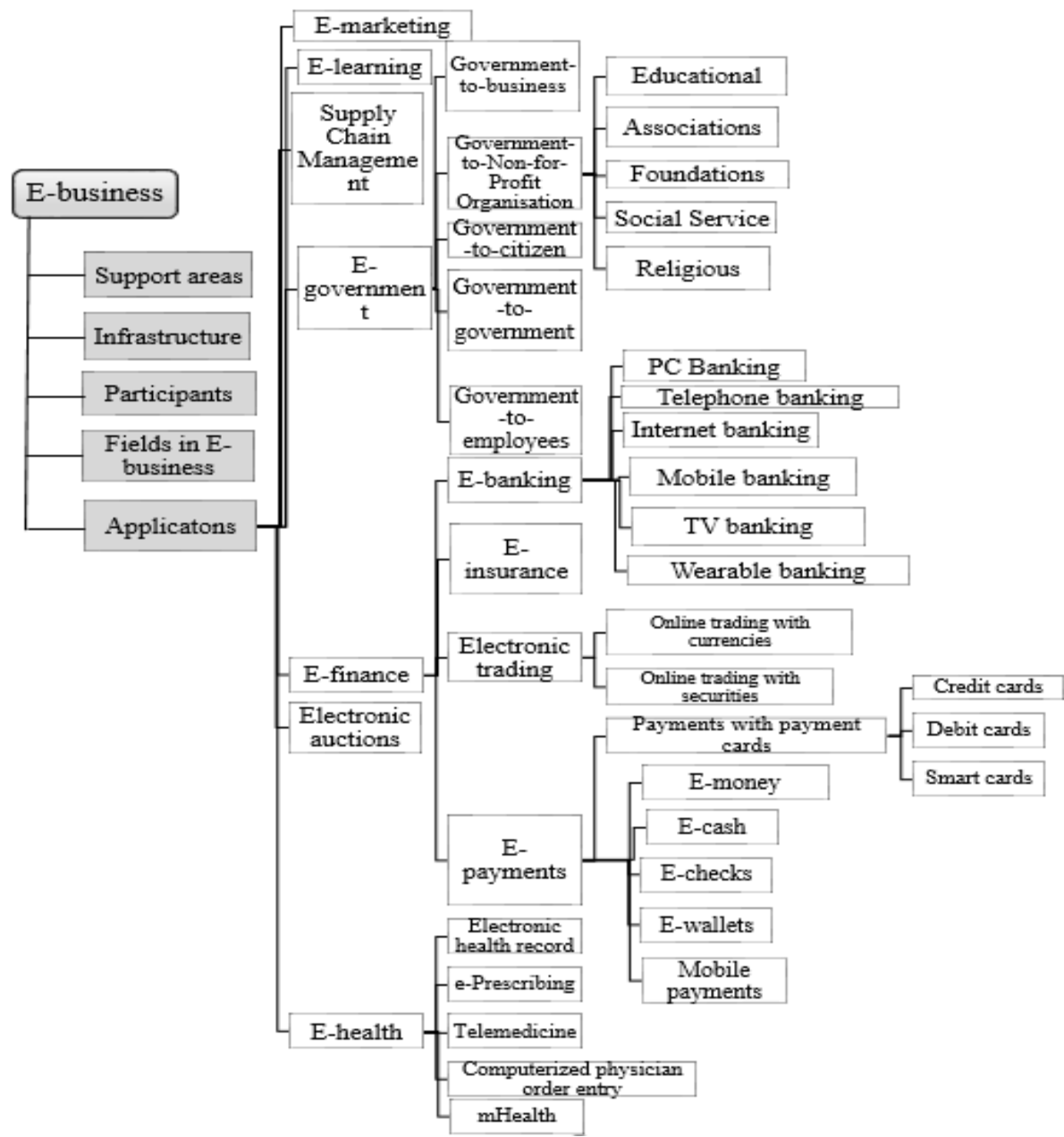

Figure 2. The Proposed Architectural Diagram of the Semantic Net of

E-business 
Figure 3 shows the developed e-business ontology for the semantic net presented in Figure 2 encoded in ontology web-based language version 2 (OWL2) using the Protégé tool Version 5.0.0 editing environment. It demonstrates that the e-business notion involves the above-mentioned super classes: e-business infrastructure, e-business support areas, e-business according to participants, fields of e-business, and e-business applications. Each of these classes involves other subclasses.

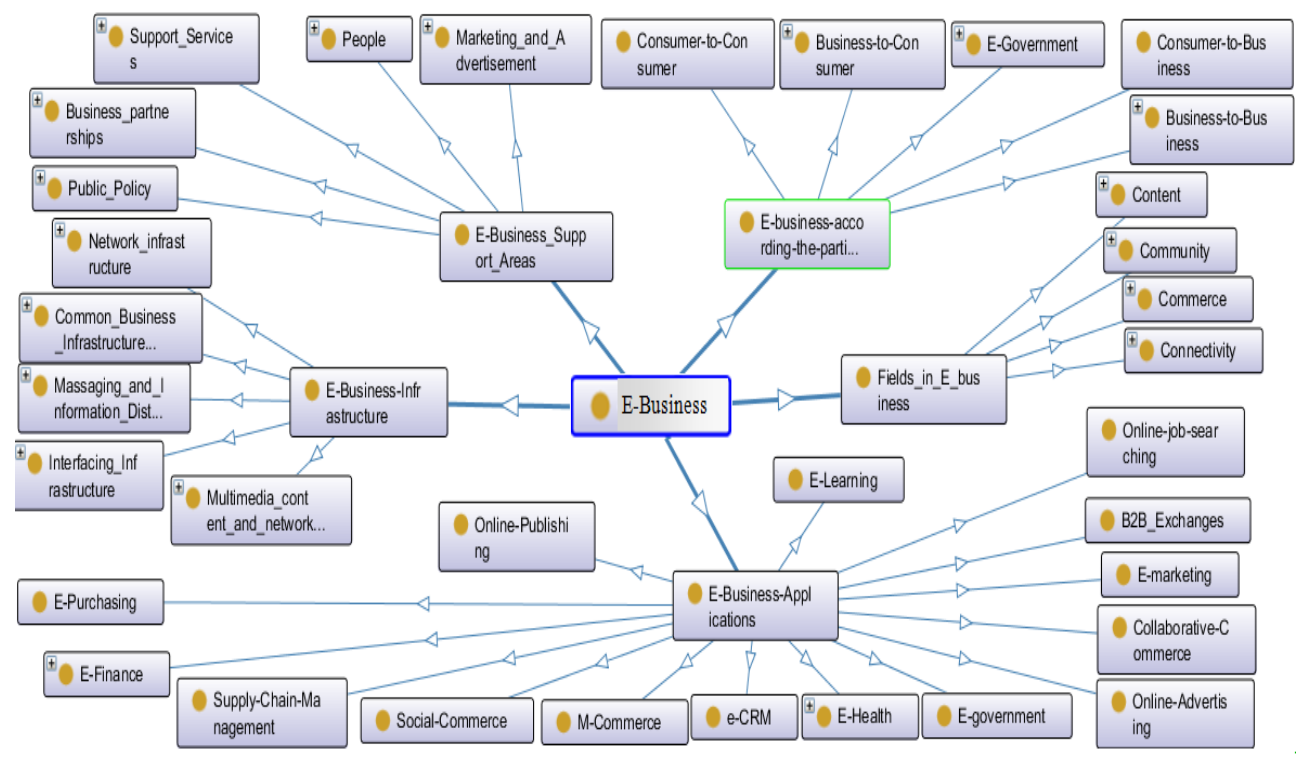

$\rightarrow \quad$ Involves

Figure 3. Developed E-business Ontology Encoded in OWL 2 and Using Protégé Tool V5 Editing Environment

Figure 4 shows that there are many e-business applications such as emarketing, supply chain management, E-CRM, e-government, e-finance, epurchasing, Business-to-Business exchanges, e-auctions, collaborative commerce, m-commerce, social commerce, e-learning, and e-health. Some of these components possess subcomponents. It is obvious that the e-finance subclass has the highest level of granularity and includes e-banking, einsurance, electronic trading, and e-payments (e-money, e-cash, e-checks, ewallets, and mobile payments). Social commerce is probably the newest component. It is enabled by social networks (and other social media tools) and online social relationships ${ }^{16}$. We believe it has great potential for growth. 


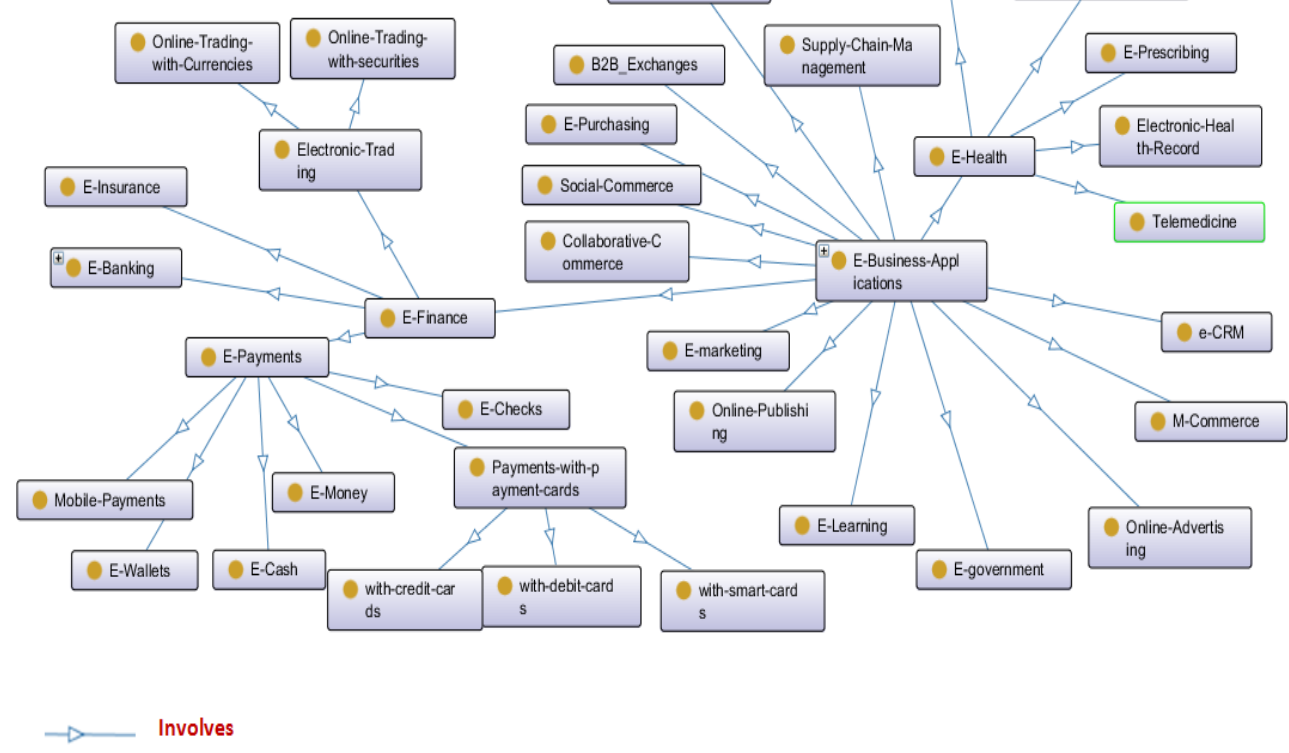

Figure 4. Developed E-business Applications' Ontology

Figure 5 demonstrates e-business ontology according to participants. The ontology consists of the e-business models, which are Business-toBusiness, Business-to-Consumer, Consumer-to-Business, Consumer-toConsumer, and the models of e-government. The e-government models involve Government-to-Business, Government-to-Consumer, Governmentto-Employee, Government-to-Government, and Government-to-Non-forProfit. 


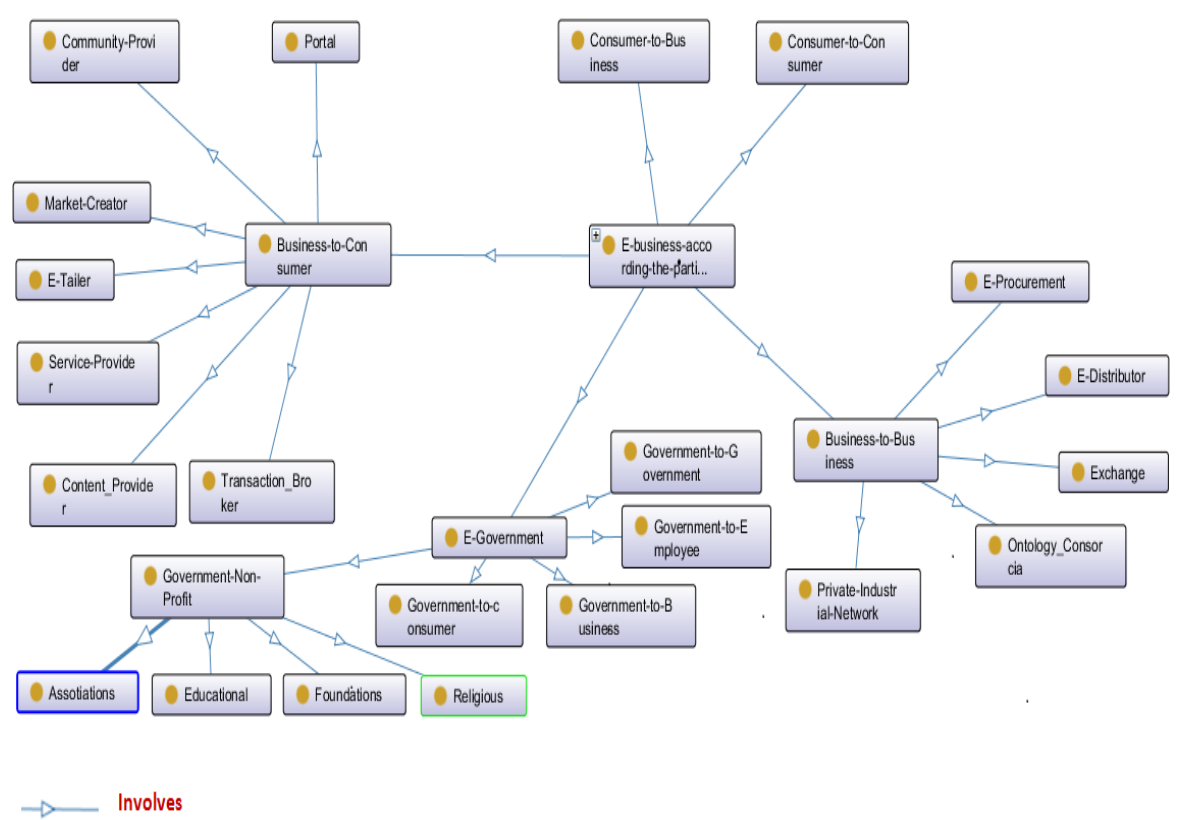

Figure 5. Developed E-business Ontology According to Participants

Figure 6 shows the e-business support areas. These areas include business partnerships, marketing and advertisement, support services, people, and public policy.

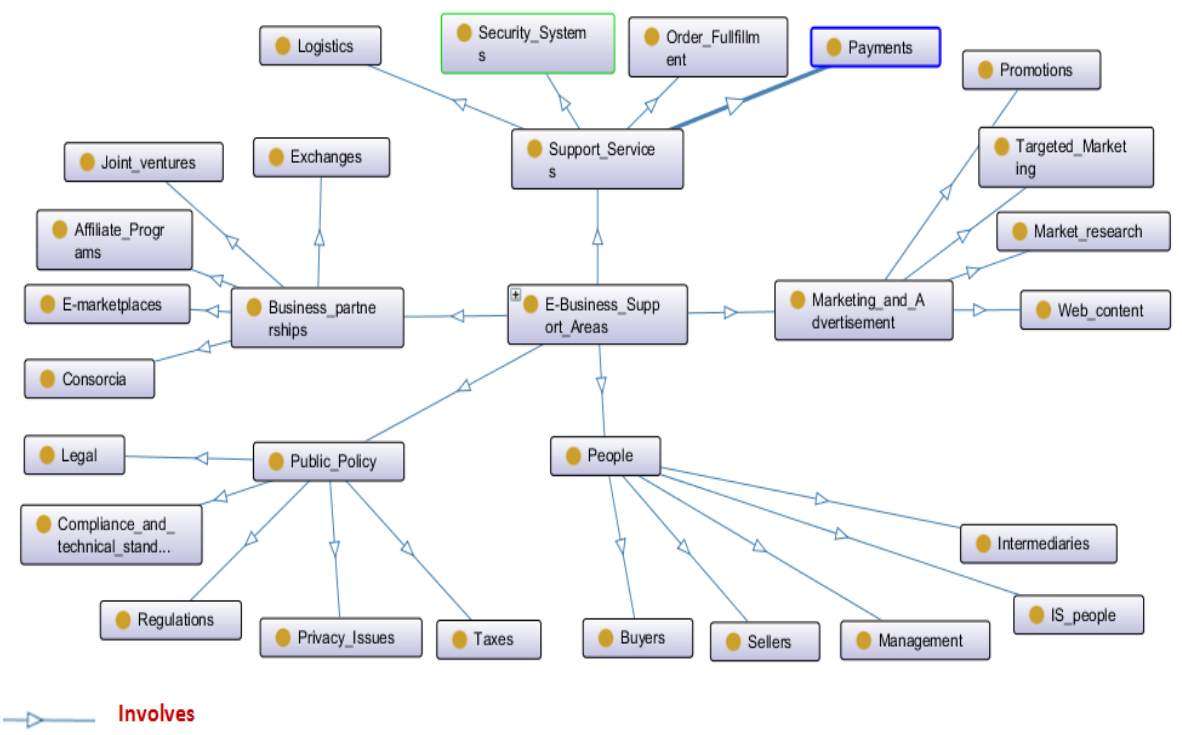

Figure 6. Developed E-business Support Areas' Ontology 
Figure 7 shows that the main class e-business infrastructure involves five subclasses, namely: common business services, massaging and information distribution, interfacing infrastructure, multimedia content and network publishing, and network infrastructure. The union between these subclasses reflects the notion of e-business infrastructure. Each of these subclasses contains other subclasses.

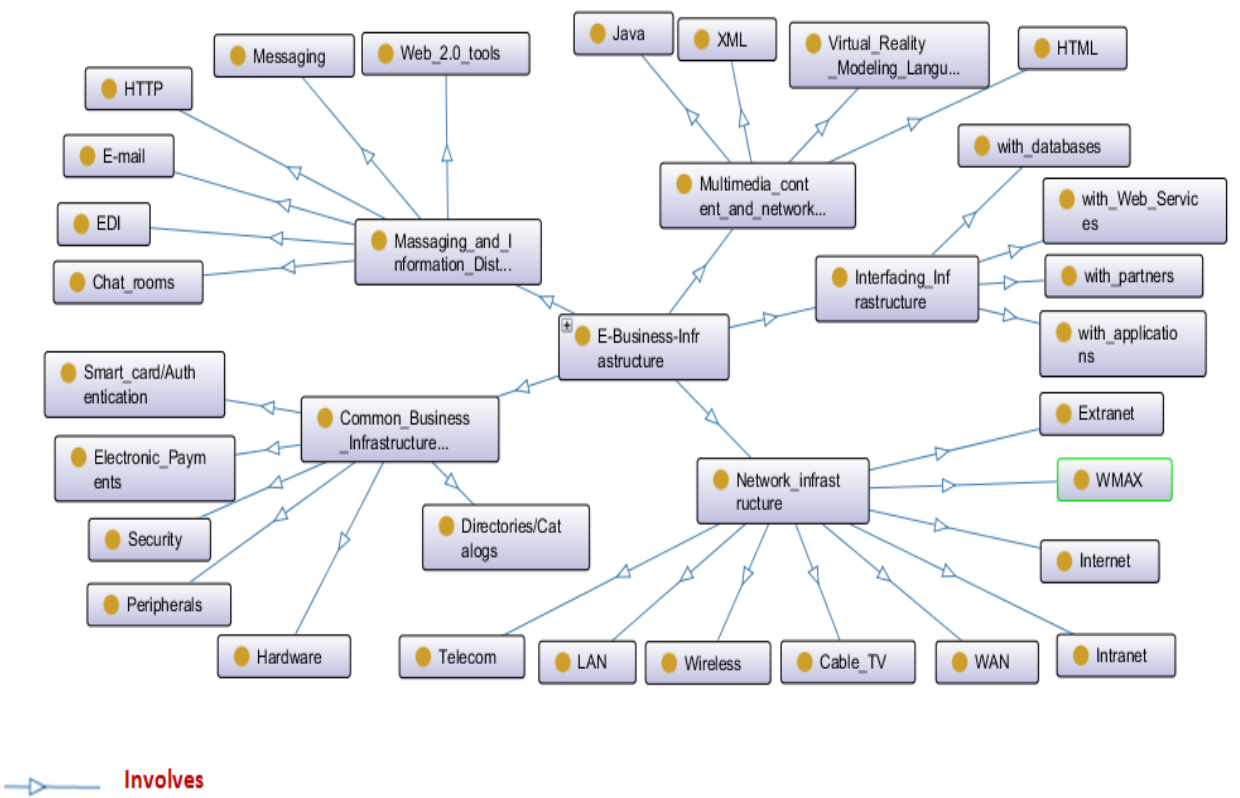

Figure 7. Developed E-business Infrastructure Ontology

The E-business fields' ontology is illustrated in Figure 8. It demonstrates four subclasses: connectivity, content, community, and commerce. Each of these subclasses contains other subclasses. 


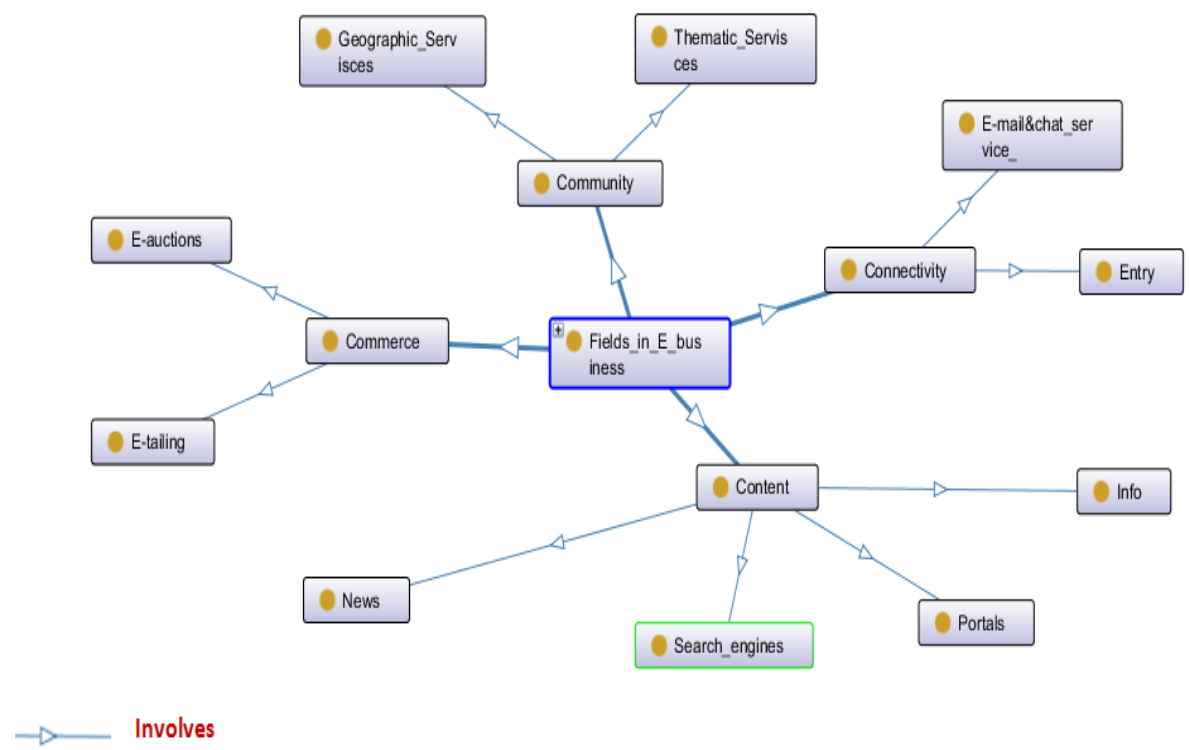

Figure 8. Developed E-business Fields' Ontology

All developed ontologies represent a robust, declarative, graphic representation technique and can be used either to represent knowledge or to support smart automated systems for reasoning about knowledge.

From a practical point of view, the proposed web-based ontologies could be useful in different applied business aspects in the area of e-business initiatives. A good example would be a new start-up company which intends to start an electronic business in the field of electronic financial services, specifically as an e-money company. The Revised European Union banking Payment Services Directive (PSD2) came into force in January 2018 with new rules. Some of these rules oblige banks to provide third-party providers access to their customers' accounts through open application program interface (APIs). Because of the changes, competition in the supply of electronic financial services is increasing and new market prospects are opened up. Thanks to this directive, new players can shape the landscape and may enter into direct competition with banks, based on the innovations and latest achievements in information and communication technologies. In the case that a start-up is looking for a niche in which to start acting, for example, as an e-money company, it should develop an e-business strategy. These developed ontologies would have practical benefits for creating the most efficient e-business strategy and would provide a good base for startups positioning in an e-business environment, specifically in electronic 
financial services. In fact, the developed web-based ontologies could help any small e-business start-up find the right approach in a variety of areas e-business applications, infrastructure, e-business players and participants, support areas, etc.

\section{CONCLUSIONS}

Ontological engineering is an efficient methodology for managing and representing knowledge. It is a logical technique for developing intelligent e-business systems. Ontologies are widely used in many informationsystems enterprises. They enable knowledge sharing and management as well as refine, reuse and search processes. Ontologies are considered the backbone of the semantic web and are used in all e-activities (e.g. ebusiness, e-economy, e-government, e-learning, e-education, e-health). Furthermore, ontological engineering enables decision makers to handle the incertitude and complexity of instructional systems. An intelligent ebusiness system based on a multi-agent approach involves a set of intelligent agents, which have to communicate with each other through messages. Agents can analyze messages using either a mutual ontology, or the interoperability between many different types of private ontologies. Ontological web-based language, OWL, is the most appropriate ontology implementation language as it is highly expressive, scalable, and possesses powerful inference capabilities.

In this paper we developed 5 web-based ontologies for e-business technology, namely: e-business applications, e-business participants, ebusiness infrastructure, e-business support areas, and fields in e-business. Overall, the results drawn by this study can assist businesses and decision makers to make fast, robust decisions. Moreover, the developed ontologies could be useful for economists, researchers, and specialists working for start-up organizations who need business knowledge to be represented in a semantic way that allows for reasoning capabilities. Our approach demonstrates that ontology development requires innovative techniques for meta-concept definition to name groups and create structure from chaos.

Our future work will be related to the fields of social business, social commerce, and social media based on their phenomenal growth and prospective increasing importance, and developing web-based ontologies for them.

Ensuring the success of such ontologies for formal case studies would also be an interesting challenge for further study. For example, we could evaluate the performance of a start-up company in e-finance, creating and starting an e-business initiative relying on the developed ontologies. 


\section{REFERENCES}

[1] M. Fernández-López, and A. Gómez-Pérez, Deliverable 1.4: A survey on methodologies for developing, maintaining, evaluating and reengineering ontologies. Part of a research project funded by the IST Programme of the Commission of the European Communities as project number IST-2000-29243, 2002.

[2] X. Su, and L. Ilebrekke, A Comparative Study of Ontology Languages and Tools, In Proceeding of the 14th Conference on Advanced Information Systems Engineering (CAiSE'02), Toronto, Canada, May 2002. http://dx.doi.org/10.1007/3-540-47961-9_62

[3] L. Tankelevciene, and R. Damasevicius, Characteristics for domain ontologies for web based learning and their application for quality evaluation. Informatics in Education, 8(1), 131-152, 2009.

[4] O. Bodenreider, and A. Burgun, Biomedical Ontologies, Medical informatics: Advances in knowledge management and data mining in biomedicine. Springer-Verlag, 211-236, 2005.

[5] T. Gruber, Ontology, Encyclopedia of Database Systems, Ling Liu and M. Tamer Özsu (Eds.), Springer-Verlag, 2009.

[6] D. Chaffey, E-Business and E-Commerce Management. Strategy, Implementation and Practice. Marketing Insights Ltd, 4th Ed., 2009.

[7] P. Wallace, Introduction to Information Systems. Pearson, 2th Ed., 2015.

[8] S. KhakAbi, M.R. Gholamian, and M. Namvar, An Ontology for EBusiness Models Based on S.C.O.P.E. of CRM. Proceedings of 8th International Conference on e-Business (iNCEB2009), 124-131, 2009.

[9] A. Osterwalder, and Y. Pigneur, An e-Business Model Ontology for Modeling e-Business. Proceedings of the 15th Bled Electronic Commerce Conference "e-Reality: Constructing the e-Economy", Bled, 2002.

[10] D. Fensel, Ontologies: Silver Bullet for Knowledge Management and Electronic Commerce, Heidelberg: Springer-Verlag, 2001. http://dx.doi.org/10.1007/978-3-662-04396-7

[11] J.D. Sternman, Business Dynamics: Systems Thinking and Modeling for a Complex World. Boston: McGraw-Hill, 2000.

[12] O. Peterovic, C. Kittl, R.D. Teksten, Developing Business Models for eBusiness. Proceedings of International Conference on Electronic Commerce 2001, Vienna, October 2001. http://dx.doi.org/10.2139/ssrn.1658505

[13] Jr.K. Rainer, Br. Prince, and C. Cegielski, Introduction to Information Systems. John Wiley \& Sons, Inc., 4th Ed., 2014.

[14] E. Turban, D. King, J.K. Lee, T.-P. Liang, and D.C. Turban, Electronic Commerce. A Managerial and Social Networks Perspective. Springer 
International, 8th Ed., 2015. http://dx.doi.org/10.1007/978-3-31958715-8

[15] S. Parusheva, K. Nestorov, and O. Marinova, Electronic Business 2nd Part. Software Development Management. Varna: Science and Economics, 2015.

[16] V.C. Joshi, E-finance: the future is here. New Delhi: Response Books, 2010.

[17] K. Laudon, and C. Traver, E-Commerce 2014. Pearson, 10th Ed., 2013.

[18] S. Parusheva, Social Media Banking Models: a Case Study of a Practical Implementation in Banking Sector, Ikonomicheski Izsledvania, 3, 125-141, 2017.

[19] J.F. Sowa, Knowledge Representation: Logical, Philosophical, and Computational Foundations. Pacific Grove, CA: Brooks Cole Publishing Co., 1999.

[20] S. Trausan-Matu, Programming in Lisp, Artificial Intelligence and Semantic Web. Iasi: Polirom, 2004. 